\title{
100 díAs, 100 AÑos. \\ La irrupción de Podemos en la CRISIS DEL RÉGIMEN POLÍTICO ESPAÑOL
}

\section{César Castañón Ares \\ Doctorando en Historia Comparada, Política y Social. Universitat Autònoma de Barcelona (UAB)}

RESUMEN: El resultado de la formación política Podemos en las elecciones europeas de 2014 superó las expectativas de todas las encuestas previas. En el presente artículo analizamos el periodo que va desde su fundación hasta esas elecciones, atendiendo a cuatro elementos fundamentales: el contexto político en el que nace la formación, las hipótesis de partida de sus promotores, los elementos centrales de su actividad en los primeros meses de existencia y las ideas fuerza de la campaña electoral para las elecciones europeas. Al final del texto analizaremos algunos de los retos a los que se enfrenta Podemos en la actualidad.

Palabras clave: Podemos, Pablo Iglesias, elecciones, crisis de régimen, 15M, España.

RESUM: El resultat de la formació política Podemos a les eleccions europees de 2014 va superar les expectatives de totes les enquestes prèvies. En el present article analitzem el període que va des de la fundació fins a aquestes eleccions, atenent a quatre elements fonamentals: el context polític en què neix la formació, les hipòtesis de partida dels seus promotors, els elements centrals de la seva activitat en els primers mesos d'existència i les idees força de la campanya electoral per a les eleccions europees. Al final del text analitzarem alguns dels reptes als quals s'enfronta Podemos a l'actualitat. 
Paraules clau: Podemos, Pablo Iglesias, eleccions, crisi de règim, 15M, Espanya.

ABSTRACT: The results Podemos obtained in the 2014 European elections exceeded the expectations of all pre-election polls. In this article we analyze the period from its founding to the elections, based on four fundamental elements: the political context in which training is born, the hypothesis of its promoters, the core elements of its activity in the first months ideas of existence and strength of the electoral campaign for the European elections. At the end of the text we discuss some of the challenges Podemos faces today.

KeYwords: Podemos, Pablo Iglesias, elections, regime crisis, 15M, Spain.

E ntre el 17 de enero y el 25 de mayo de 2014 pasaron 129 días. La primera es la fecha en la que Podemos se presentó públicamente, en el Teatro del Barrio de Lavapiés, Madrid; el segundo es el día de las elecciones europeas, en las que la candidatura encabezada por Pablo Iglesias y Teresa Rodríguez-Rubio obtuvo 1.245.948 votos, cinco eurodiputados, y se convirtió en cuarta fuerza política del Estado español en el Parlamento Europeo. ${ }^{1}$

Analizar los elementos clave de la irrupción de Podemos en el panorama político implica tener en cuenta la posición desde la que lo hacemos y los riesgos que ello conlleva, que son al menos dos. Por un lado, porque lo haremos a posteriori. Que hoy escribamos sobre los orígenes de Podemos se debe, en última instancia, al éxito de la iniciativa, cuyo resultado desconocían quienes tuvieron la responsabilidad de tomar las decisiones que marcaron su desarrollo. Corremos el riesgo de que, al hacer este análisis desde ese éxito, perdamos de vista los miedos y los peligros sentidos por quienes lo gestaron

1. Datos del Ministerio del Interior. Gobierno de España <http://elecciones.mir.es/ resultados2014/99PE/DPE99999TO.htm> [consultado el 17 de junio de 2014]. 
y tendamos a considerarlo más el resultado de unas condiciones estructurales que el fruto de acciones humanas en un contexto concreto. Ambos factores son, sin duda, decisivos.

El segundo riesgo lo entraña la posición concreta del autor. El que escribe estas líneas no es sólo un ciudadano influido por la realidad política en la que vive, como cualquier otro analista. También es parte integrante de Podemos desde sus primeros pasos y como tal no puede sustraerse de la influencia de la experiencia cercana. No tiene este artículo objetivos laudatorios. Espero que estas líneas sirvan para no olvidar que Podemos no fue siempre primera fuerza en intención directa de voto, y a su vez para tener siempre presentes algunos de los aspectos estratégicos y tácticos fundamentales que hicieron posible el salto de Podemos al centro del tablero político español. A pesar de la cercanía de los hechos aquí referidos, y de la implicación que he tenido en ellos, ha sido mi firme propósito escribir, como exigían los clásicos, sine ira, et studio.

Para llevar a cabo el análisis que nos planteamos e intentar explicar algunas de las claves de la breve historia de Podemos, dividiremos las siguiente páginas en cinco apartados. El primero estará dedicado a la situación política general en las que se dieron las pasadas elecciones europeas. Nos ayudará a entender por qué en ese momento y quizá no en otro una candidatura de nuevo cuño podía cosechar un éxito electoral de gran magnitud. En el segundo intentaremos explicar, a partir de algunos materiales publicados por Podemos, cuál era la hipótesis de partida de sus promotores, desde la que veremos en qué medida el éxito se remite a sus premisas. El tercer apartado lo dedicaremos a destacar algunos de los elementos centrales en la actividad de los primeros meses de Podemos, entre enero y abril, que en mayor o menor medida definieron las particularidades del proyecto. En cuarto lugar nos ocuparemos de la campaña electoral propiamente dicha, cuáles fueron los elementos fuerza que, más allá de las condiciones estructurales, hicieron posible el resultado obtenido. En el último apartado señalaremos algunos de los retos a los que se enfrenta Podemos en el momento de realizar su primer congreso, denominado Asamblea Ciudadana «Sí se puede», a partir de los elementos previamente analizados. 


\section{Las elecciones europeas. Entender Podemos a posteriori}

Los resultados de las elecciones europeas de 2014 lanzaron a la primera línea del debate público una situación de la que hace tiempo venían alertando intelectuales de muy diversa procedencia. Aunque los inicios de la crisis del capitalismo financiero globalizado generaron principalmente reacciones de apatía, pesimismo y soledad, que sorprendieron a buena parte de la izquierda, su desarrollo, especialmente desde el bienio 2010-2011, ha dado pie a grandes oleadas de movilización social en partes muy importantes del planeta, y está generando una creciente crisis de la hegemonía neoliberal, que nos lleva hacia un periodo de cesura histórica, en el que «todas las certezas son puestas en duda, muere lo viejo y en su muerte puede que se lleve todo aquello de bueno que había en nuestras sociedades, sin dejar aún, que nazca lo nuevo» (Domènech, 2014, p.72).

Dicha crisis de hegemonía toma la forma, dentro de nuestras fronteras, de una crisis del régimen político que se fue configurando a partir de los Pactos de la Moncloa, de la constitución escrita de 1978 y, más tarde, de la incorporación del Reino de España al bloque geoeconómico y militar occidental. Las expresiones de esta situación pueden resumirse en tres grandes factores: los conflictos nacionales que tensionan los límites de las instituciones estatales, las dificultades para superar el cerco de la deuda en el marco del euro y de la Unión Europea, y el descrédito de los partidos políticos y de sus principales dirigentes (Pastor, 2013).

Una panorámica general de los resultados del pasado 25 de mayo nos permite observar una tendencia común en casi toda Europa que se está agudizando en los meses posteriores: el hundimiento de los partidos socialdemócratas y liberales, garantes en las últimas décadas del pacto neoliberal $-\mathrm{y}$ de sus diferentes actualizaciones, que en la Unión Europea toman forma concreta en el Tratado de Maastrich, la Constitución Europea, el Tratado de Lisboa y, más recientemente, el todavía no aprobado Tratado de libre comercio entre Estados Unidos y la Unión Europea (TTIP) - , que contrasta con el ascenso en la mayor parte de los casos, de opciones de extrema derecha identitaria, que se refugian en la afirmación nacional y utilizan como arma el odio al extranjero (Urban, 2014 a, 2014 b y 2010). La victoria en Francia del Frente Nacional — con un $24,86 \%$ de los vo- 
tos - y en el Reino Unido de UKIP (Partido por la Independencia de Reino Unido, con un 26,77\%) son las máximas expresiones de una situación extendida en el continente. Sólo en Grecia y en España encontramos un claro ascenso del voto a opciones de izquierdas que se afirman solidarias con el conjunto de pueblos europeos. En el caso griego, el ascenso de Syriza en las urnas - primera fuerza con un $26,60 \%$ de los votos- es deudor tanto del fracaso de las políticas de austeridad aplicadas por socialdemócratas y liberales, como del conflicto social sostenido contra las políticas de la troika, especialmente en las más de 30 huelgas generales llevadas a cabo entre 2009 y 2014; pero también en movimientos replicantes del 15M, como lo fue el de la plaza Syntagma de Atenas.

En el estado Español, el retroceso de las movilizaciones directamente herederas del movimiento $15 \mathrm{M}$ dio paso a un nuevo ciclo «donde las clases subalternas ya no se conforman con protestar, sino que buscan convertir su propio relato en poder político» (Fernández, 2014). Encontramos los primeros síntomas de este cambio de ciclo en Cataluña, con la entrada de las CUP en el Parlament, en noviembre de 2012, y posteriormente el éxito del llamamiento realizado por Arcadi Oliveres y Teresa Forcades para construir un movimiento político en favor de un proceso constituyente catalán, en abril de 2013. Podemos aparece en este panorama como un experimento audaz, pero formando parte también de procesos más amplios de reorganización social y política, algunos previos, muchos desarrollándose en paralelo. Y su éxito sólo puede entenderse como la combinación de, al menos, tres elementos: la crisis de hegemonía a la que nos hemos referido en este punto; la mayoría social indignada que se movilizó o simpatizó con el 15M, la PAH o las Marchas de la Dignidad; y la propia capacidad de toda las personas que han participado en la creación de Podemos para construir una herramienta a la altura de las circunstancias. Éste último factor será el que centre nuestra atención en las próximas páginas.

\section{Origen e hipótesis de Podemos. Crisis de régimen y mayoría social}

El lanzamiento de Podemos fue uno de esos momentos que sólo pueden adjetivarse desde el futuro, con cierta perspectiva histórica. En caso de tener 
éxito - como así ha sido - es calificado como de movimiento audaz; si hubiese fracasado, habría sido una locura irresponsable - como muchos ya lo calificaron en sus inicios- Pero sin lugar a dudas, desde buen inicio, éste ha sido un proyecto que ha trastornado las agendas de la izquierda política establecida, poniendo sobre la mesa elementos metodológicos, organizativos y en última instancia políticos, que durante mucho tiempo estuvieron fuera del debate en los partidos con representación parlamentaria.

Para valorar en su justa medida el éxito de Podemos es necesario tener claro cuál era su hipótesis de partida, entender con precisión qué era lo que sus promotores buscaban conseguir. De otra manera, corremos el riesgo de hacer un análisis basado tan sólo en encuestas y previsiones electorales, reduciendo con ello los objetivos y responsabilidades de este movimiento político a una cuestión de volumen de votos.

La presentación de Podemos se llevó a cabo a través del manifiesto Mover ficha: convertir la indignación en cambio político, que apareció en los medios de comunicación el 14 de enero de 2014, y de una rueda de prensa celebrada tres días después, en el Teatro del Barrio de Lavapiés, Madrid. Entre los protagonistas y auspiciadores de la iniciativa se encuentran algunas figuras destacadas de la organización política Izquierda Anticapitalista, como Teresa Rodríguez-Rubio y Miguel Urbán, y varias de las personas que junto a Pablo Iglesias impulsan el programa de televisión La Tuerka, como Juan Carlos Monedero e Íñigo Errejón; a los que se unieron activistas e intelectuales de diversa procedencia.

Ese manifiesto sintetiza ya los planteamientos que en los meses sucesivos escucharíamos de manos de sus portavoces, que se resumen en cuatro puntos:

a. La constatación de que existe una mayoría social indignada frente a la situación generada por la crisis y las políticas neoliberales que aplican los Gobiernos; y a su vez, no existe ninguna «opción electoral que emocione y que, al tiempo, demuestre capacidad de representación de las mayorías golpeadas y capacidad de gestión eficiente y comprometida que haga reales las mejores opciones posibles» (VVAA, 2014, p. 1). Podemos se postularía como esa opción electoral. 
b. La necesidad de construir tanto un nuevo lenguaje como nuevos métodos de hacer la política. Un lenguaje «que hable como la mayoría de la gente que está harta», y una metodología que permita a la gente «tomar nuestras propias decisiones y responder a nuestras propias preguntas» (VVAA, 2014, p. 2), a través de mecanismos de horizontalidad y transparencia que permitan interpelar a la mayoría social que se busca articular.

c. La voluntad de desbordar los marcos de la hegemonía política actual, y con ella, los límites políticos y discursivos de la izquierda, a través de una candidatura «encabezada por personas que expresen nuevas formas de relacionarse con la política y que suponga una amenaza real para el régimen bipartidista del PP y del PSOE y para quienes han secuestrado nuestra democracia»».

d. Un esbozo programático en ocho puntos que recoge reivindicaciones de movimientos sociales como la Plataforma de Afectados por la Hipoteca, la Plataforma por la Auditoria Ciudadana de la Deuda, las mareas en defensa de la educación y la sanidad públicas, el movimiento feminista o el movimiento por el derecho a decidir en Cataluña.

A estos cuatro elementos, que delimitan desde el punto de partida los horizontes de trabajo, se añade un quinto, la presencia de Pablo Iglesias como portavoz y cabeza visible, que actúa como catalizador de todo lo anterior. La presencia de Iglesias le dio desde el comienzo un poder a Podemos del que habría carecido de otra manera. Sin la propiedad de grandes medios de comunicación y sin el dinero necesario para tener presencia en los existentes, a la mayor parte de movimientos sociales y políticos les resulta imposible establecer vías de contacto con la ciudadanía a la que pretenden interpelar, que se socializa a través de la televisión y, en menor medida, de la radio y la prensa escrita.

Sin que por ello pierda su originalidad y sus especificidades, no debemos dejar de señalar que Podemos no es un proyecto nacido de la nada. Además de la acumulación de experiencias que sus promotores hayan podido depositar en él, su análisis y su configuración se inspira también en experimentos 
exitosos recientes. Es el caso de Alternativa Galega de Esquerda (AGE), una coalición que se presentó a las elecciones al parlamento de Galicia en octubre de 2012 , obteniendo un $14 \%$ de los votos, muy por encima de lo que las encuestas les auguraban. También del éxito de las Candidatures de Unitat Popular (CUP), que después de una larga experiencia de trabajo municipalista, marcaron un hito histórico al conseguir tres diputados la primera vez que se presentaron a unas elecciones al Parlamento catalán, en noviembre de 2012. Y por último, siendo quizá el proyecto que más se acerca al método y las prácticas organizativas que Podemos planteó en sus inicios, encontramos al Procés Constituent, movimiento político en clave catalana, impulsado en abril de 2013 por Teresa Forcades y Arcadi Oliveres, que ha conseguido poner en el centro del debate entre las izquierdas catalanas la necesidad de construir un bloque político unitario frente a las políticas neoliberales y a favor de un proceso constituyente catalán.

\section{El cómo y el qué. Las primeras encrucijadas}

Al lanzamiento de Podemos le siguieron una serie de hitos que determinaron la acogida del proyecto entre activistas sociales y políticos, pero también en la mayoría social a la que apelaba. En un primer momento se lanzó una campaña de recogida de avales por Internet, que se saldó en pocos días con la obtención de 100.000 apoyos, el doble de lo que los promotores se habían marcado como mínimo para seguir adelante. Muy seguidamente comenzó la creación de círculos Podemos, asambleas abiertas a toda la ciudadanía y autogestionadas, creadas en la mayor parte de los casos por personas sin relación directa con los promotores del proyecto. El 2 de marzo, los portavoces anunciaban que su número era cercano a los 200, y el 22 de junio, su página de Facebook celebraba la existencia de más de 500 círculos. En el momento de celebrarse el primer congreso — la Asamblea Ciudadana «Sí Se Puede»—, en noviembre, existían más de 1.000 círculos.

En una segunda fase de lanzamiento se organizaron unas elecciones primarias abiertas, presentadas como una de las señas de identidad del proyecto, que generaron cierta polémica entre diversos sectores de la izquierda. El objetivo explícito de las mismas era que cualquier persona pudiese votar, con la 
sola condición de tener un teléfono móvil; y también que cualquier persona pudiese presentarse, para lo cual debía obtener el aval de alguno de los círculos existentes en aquel momento. El resultado fueron unas elecciones realizadas por Internet, entre el 27 de marzo y el 2 de abril, a través de la plataforma Agora Voting, en las que se postulaban 145 candidatos y candidatas para configurar una lista de 54, más 10 suplentes, con corrección de género en formato cremallera —alternando hombre-mujer-hombre-, y en las que votaron más de 33.000 personas, consiguiendo con ello la mayor participación en unas elecciones de este tipo en Europa.

El último de estos procesos previos a la campaña electoral fue la elaboración del programa. Partiendo de los puntos esbozados en el manifiesto Mover Ficha, el equipo promotor hizo público un borrador de programa y estableció una serie de plazos para las aportaciones externas, tanto de manera individual, en las que pudo enviar propuestas cualquier persona con acceso a Internet, como colectiva, a través de los círculos. En conjunto, según anunciaron los organizadores en el Encuentro Ciudadano celebrado el 12 de abril en Madrid, se habían recibido más de 1.000 aportaciones. Finalmente, las propuestas recibidas fueron compiladas, adaptadas al formato con el que se había elaborado el borrador y votadas durante unos días a través de Internet. El resultado fue un programa deudor del trabajo realizado durante los últimos años por diversos movimientos sociales. Y a su vez, heredero de una tradición de largo recorrido, la del movimiento democrático que se inicia en la Revolución francesa, que sobrevive a través del tiempo en las mejores tradiciones del movimiento obrero y del republicanismo democrático, y que después de la segunda Guerra Mundial plasmará sus fundamentos en la Declaración Universal de Derechos Humanos de 1948. Esta síntesis de pasado y presente, de tradición e innovación, se expresaba en uno de los panfletos que los simpatizantes de Podemos repartieron durante la campaña; decía: «Podemos nació hace unos 100 días para defender ideas que tienen más de 100 años: democracia y soberanía, trabajo y dignidad».

La principal victoria de Podemos en estos primeros meses de organización fue su capacidad para no evitar las tensiones internas y ser capaz de salir reforzada con ellas. Tanto en las elecciones primarias como en la elaboración del programa o en la creación de los círculos, se produjeron numerosos con- 
flictos que son prueba de la vitalidad del movimiento y de la diversidad de procedencias y experiencias previas de quienes lo construyen. En su capacidad para mantener estos conflictos en su seno y ser capaz de seguir creciendo con ellos, se encontrará sin duda una de las claves de su futuro.

\section{La campaña electoral. La ilusión y lo posible}

Las cifras de participación registradas por Podemos antes de las elecciones europeas ya nos permitirían catalogarlo como el movimiento político de mayor impacto y extensión conocido en el estado Español en las últimas décadas — quizá, desde la creación de Izquierda Unida —, y sin embargo se encuentran todavía muy lejos de las cifras de votos obtenidas en las elecciones.

Parte de que la posible explicación de dichos resultados se encuentra en factores externos a la propia actividad de Podemos, ligados a la crisis de régimen y al último ciclo de movilizaciones, como ya hemos mencionado. Pero otra parte se debe a la actividad misma de sus impulsores, que tuvo su expresión de mayor intensidad durante la campaña electoral. Son las claves mismas de la campaña las que nos permiten entender que un proyecto político nuevo, con una organización embrionaria, sea capaz de interpelar a la sociedad con fuerza suficiente para conseguir el apoyo de 1,2 millones de personas.

Para entender este salto cuantitativo pondremos en consideración tres aspectos de la campaña electoral que consideramos centrales: el papel de Pablo Iglesias y su presencia en los medios de comunicación; la creación de un discurso político basado en las principales preocupaciones de la ciudadanía española; y finalmente, la presencia de Podemos en las encuestas electorales y su capacidad performativa.

La popularidad adquirida por Pablo Iglesias a través de su participación en algunas de las principales cadenas televisivas privadas fue, desde el primer momento, un activo aprovechado por los promotores de la formación para darlo a conocer y obtener simpatías. El discurso desarrollado por Iglesias en su experiencia previa en televisión ha sido una de sus bases comunicativas, a la que se han ido agregando elementos nuevos en la campaña electoral. El relativo desconocimiento que la población tenía de Podemos, al menos en comparación con la popularidad de su cabeza de lista, generó en todo momento 
una situación de dependencia respecto de un sólo portavoz, que en los meses posteriores se ha reducido notablemente. A pesar de lo cual, Iglesias sigue siendo una pieza determinante de su engranaje. Es difícil saber qué porcentaje de votantes conocían el 25 de mayo a Podemos y cuántos a Pablo Iglesias, es más que probable que utilizar su cara como logotipo en las papeletas de la candidatura facilitase la obtención del voto, pero a su vez ponía de manifiesto una de las debilidades iniciales del proyecto.

El principal éxito de la campaña llevada a cabo por Podemos en estos meses ha sido desplazar el eje de la política desde el enfrentamiento entre izquierdas y derechas, en el que estaban cómodamente asentados los partidos dominantes, a la confrontación entre la «gente» y la «casta». La existencia de este nuevo eje político habría sido imposible sin algunas consignas que fueron centrales en experiencias de movilización previas; el «somos los de abajo y vamos a por los de arriba» que se popularizó en el movimiento de los indignados, o el «somos el 99\%», que nos llegó desde el Occupy de Estados Unidos. A su vez, supone una nueva forma, más desarrollada que las anteriores, de poner la lucha de clases en el centro de la política; pero no una lucha de clases en la que los bandos están sociológica y programáticamente predefinidos, sino un proceso en el que la construcción de una conciencia social colectiva es el resultado de la acción social y política, de las experiencias de la gente en su contexto vital concreto. Las repetidas ocasiones en las que Pablo Iglesias aprovechó los mítines de campaña para explicar la fábula de Mouseland, tomada del político canadiense Tommy Douglas, son la expresión más explícita - y a su vez, alegórica - de tal voluntad.

El discurso desarrollado durante la campaña centró su atención en los problemas que la mayor parte de la población considera centrales en el país (Centro de Investigaciones Sociológicas, 2014): la corrupción política, frente a la que Podemos plantea una batería de medidas concentradas en la llamada Directiva Villarejo - que toma su nombre del ex fiscal anticorrupción y número 3 de la lista electoral, Carlos Jiménez Villarejo-; los problemas derivados de la crisis económica, ante los cuales plantea la realización de una auditoría de la deuda, una reforma fiscal para elevar la cotización de las grandes fortunas y la persecución del fraude; y finalmente, los problemas relacionados con el sistema político y los políticos, centrando su crítica en el bipartidismo 
dominante en las últimas décadas y popularizando el término casta para referirse a los cargos públicos que han hecho de la política una profesión de vida.

La campaña dejó en un segundo plano temas que, valorados desde otros parámetros, podrían tener la misma o mayor importancia, pero que no son así percibidos por la mayoría social con la que se pretende interlocutar. Y en esta cuestión se establece una relación difícil entre discurso y programa. Mientras el programa recoge respuestas a cuestiones de actualidad, como la reforma de la Ley del Aborto, el conflicto político en Cataluña o la llegada de migrantes a España a través de Ceuta y Melilla, a las que un gobierno debe ser capaz de responder, éstas quedan en un segundo plano en el discurso público de Podemos. La dialéctica entre un programa que demuestre la «capacidad de gestión eficiente y comprometida que haga reales las mejores opciones posibles», planteada en el manifiesto Mover Ficha (vvAA, 2014), y la necesidad de interpelar a través del discurso a una mayoría social que comienza a movilizarse, pero que en la actualidad sigue manteniendo índices muy bajos de participación política (Centro de Investigaciones Sociológicas, 2014), es una de las dificultades a las que se enfrenta Podemos en la actualidad.

Si bien en un primer momento la aparición de Podemos no fue considerada noticia por la mayoría de medios de comunicación, con la excepción de algunos diarios digitales - especialmente, publico.es y eldiario.es-, el desarrollo de la de la campaña hizo que su presencia en las encuestas demoscópicas creciera. Muy significativamente, en las encuestas de Metroscopia para El País, Podemos empieza a aparecer en febrero, con un $0,4 \%$ de intención directa de voto, y va creciendo hasta alcanzar, en el barómetro publicado el 20 de mayo, un 2,4\% en la estimación de resultado electoral (Ferrándiz, 2014 a, 2014 b, 2014 c y 2014 d). Situaciones similares se dieron en otras encuestas. El Centro de Investigaciones Sociológicas y Sigma Dos otorgaban, a 19 de mayo, un escaño a la candidatura. Por su parte, Sondea Investigación Social, que fue la encuesta que más se acercó a los resultados finales de las elecciones en todos los casos, le daba 2-3 eurodiputados. Este crecimiento acelerado en las encuestas demuestra la efectividad de la campaña electoral, pero a su vez debemos considerar que éstas tienen un carácter performativo, reducen la presión que el voto útil ejerce sobre las candidaturas nuevas y en este caso 
concreto hicieron aparecer a Podemos como una opción al alza, un voto que garantizaba representación.

\section{Conclusiones. Los retos de Podemos en la actualidad}

Seis meses después de las elecciones europeas Podemos se ha transformado de manera notable en diferentes aspectos. La Asamblea Ciudadana «Si Se Puede» ha convertido lo que inicialmente se definió como un «método ciudadano« y un «movimiento político» en un partido político, con un objetivo central definido: ganar las próximas elecciones generales, que condicionará su actividad en el futuro inmediato.

En el momento presente, Podemos ha conseguido articular una conciencia social fuerte, con voluntad de ser mayoritaria, que crece a ritmo vertiginoso y cuyos límites es difícil vislumbrar. El principal reto al que se enfrenta en el próximo periodo es convertir esa conciencia social en conciencia política, en acuerdos respecto de cómo debe articularse y organizarse el cambio político en los términos que plantea. Los consensos de mínimos que definen esa conciencia social común se basan en los ejes desarrollados en el discurso de campaña, que a su vez ha funcionado como núcleo de articulación política de los círculos. Sin embargo, los retos a los que deberá enfrentarse Podemos van mucho más allá de las consignas de campaña.

Debemos tener en cuenta que la mayor parte de las herramientas utilizadas por Podemos para conseguir su éxito inicial son a su vez señales de su fragilidad. Por un lado, la dependencia de un líder mediático — señalada por el mismo Pablo Iglesias como el resultado de la debilidad de la izquierda preexistente - genera dudas que han sido manifestadas en la propia Asamblea Ciudadana respecto de la capacidad de Podemos para construir proyectos fuertes a nivel local. Por otro, el discurso desarrollado en la campaña electoral y hasta el momento presente ofrece importantes ventajas para el debate en medios de comunicación, pero a la vez es signo de la ausencia de sociedad civil organizada en España, sin cuyo apoyo parece difícil que un proyecto de cambio de régimen político pueda resultar exitoso.

Para hacer frente a las debilidades de partida, la única herramienta con la parece contar Podemos hasta el momento son los círculos. Si éstos son capa- 
ces de desarrollar proyectos políticos fuertes a escala local, que aprovechen las posiciones ya ganadas a escala estatal, podrán superar la dependencia de la estructura central del partido. Que lleguen o no a conseguir esto dependerá a su vez de la capacidad para convertirse en polos de reorganización del tejido civil en sus ámbitos de influencia. En caso de que los círculos no sean capaces de hacer esto, Podemos corre el riesgo de acabar convertido en un aparato político funcional en lo discursivo, pero sin raíces que le permitan mantenerse en el centro del tablero político en el medio y largo plazo.

\section{Referencias}

Centro de Investigaciones Sociológicas (2014): Estudio no $n^{\circ}$ 3021. Barómetro de abril 2014. En: < http://www.cis.es/cis/export/sites/default/-Archivos/Marginales/3020_3039/3021/es3021mar.pdf $>$.

Cercle D'Economia (2013): Fi de Cicle. Temps Nou. En: $<$ http://www.circuloeconomia.com/download.php? $\mathrm{f}=$ opiniones_documentos/Opiniy_CAT.pdf $>$.

DomèneCh, X. (2014): Hegemonías. Crisis, movimientos de resistencia y procesos políticos (2010-2013), Akal, Madrid.

Fernández, B. (2014): «Podemos, un gran acierto y una gran responsabilidad». En: <http://www.vientosur.info/spip.php?article9156>.

Ferrandiz, J. P. (2014 a): Elecciones europeas. Barómetro preelectoral: febrero 2014. En: <http://blogs.elpais.com/metroscopia/2014/02/barometro-preelectoral-elecciones-europeas-febrero-2014.html>.

- (2014 b): Elecciones europeas. Barómetro preelectoral: marzo 2014. En: $<$ http://blogs.elpais.com/metroscopia/2014/03/elecciones-europeas-barometro-preelectoral-marzo-2014.html>.

- (2014 c): Elecciones europeas. Barómetro preelectoral: abril 2014. En: $<$ http://blogs.elpais.com/metroscopia/2014/04/elecciones-europeas-barometro-preelectoral-abril-2014.html $>$.

- (2014d) Elecciones europeas 2014. Último sondeo preelectoral. En: $<$ http://blogs.elpais.com/metroscopia/2014/05/elecciones-europeas-2014-ultimo-sondeo-preelectoral.html>.

Gómez, Ly M. ViEJo (2014): «Las redes de arrastre de Podemos». En: < http:// politica.elpais.com/politica/2014/05/28/actualidad/1401305050 166293. $\underline{\text { html }}$. 
Pastor, J. (2013): «Crisis de régimen y refundación (im)posible». En FerNÁNDEZ, J. Y M. URBAN (eds.): Crisis de régimen y procesos constituyentes, VientoSur, 128, pp.17-26.

Rico, J. (2014): «Podemos lograría 58 escaños en el Congreso a costa del PSOE e IU». En: <http://www.elperiodico.com/es/noticias/politica/podemos-sondeo-gesop-escanos-congreso-3294073>.

Sanmartín, O. (2014): «El mediático Pablo Iglesias logra cinco escaños inesperados». En: <http://www.elmundo.es/espana/2014/05/25/538264f4ca4741066a8b456b.html>.

Sondea Investigación Social (2014): «Estimación de resultados». En: $<$ http://sondeainvestigacionsocial.com/elecciones-al-parlamento-europeo/intencion-de-voto-y-estimacion-de-resultados $>$.

Urban, M. (2010): «Una Europa en crisis y una extrema derecha en ascenso», en Viento Sur, 110, pp. 33-42.

— (2014 a): «La derecha radical y el populismo multiforme». En: $<\underline{\text { http: } / / \text { www. }}$ miguelurban.net/2014/03/03/la-derecha-radical-y-el-populismo-multiforme $>$.

- (2014 b): «Radiografía de la extrema derecha ante las europeas». En: $<$ http://www.miguelurban.net/2014/03/24/radiografia-de-la-extrema-derecha-ante-las-europeas $>$.

VvaA (2014): «Mover ficha: Convertir la indignación en cambio político». En: $<$ http://es.scribd.com/doc/199547061/Manifiesto-Mover-Ficha $>$. 
